\title{
DISSERTAÇÃO DESSEMELHANTE: EDUCAÇÃO ESQUIZITA OU POR UMA VIDA NÃO FASCISTA EM UMA ACADEMIA
}

\section{DISSIMILAR DISSERTATION: ESQUIZITA EDUCATION OR FOR NON- FASCIST LIFE AT THE ACADEMY}

\author{
Sônia Maria Clareto ${ }^{1}$ \\ Tarcísio Moreira Mendes ${ }^{2}$
}

\begin{abstract}
Resumo: Há dois anos, nas redes sociais, um ataque paranoico a uma dissertação de mestrado em educação foi usado para questionar a racionalidade das produções das Ciências Humanas. A partir da incompreensão da Pró-Reitoria de Pesquisa, que desejava entender como uma dissertação em formato tão dessemelhante fora defendida, põe-se a pensar. Hoje, a racionalidade de todas as Ciências é atacada por um inconsciente fascista que se instalou no Estado. Ironicamente, os autores dos ataques à dissertação agora se sentindo vítimas da paranoica instalada no Estado, identificam como causa a doutrinação de "gurus das redes sociais". Problematiza-se, desse modo, como um delírio paranoico pode potencializar um inconsciente reacionário que vitima principalmente aquele que o produz. Sobretudo, como a denúncia do segregativo reacionário pode disparar potencialidades revolucionárias na pesquisa científica.
\end{abstract}

Palavras-chave: Pesquisa acadêmica; esquizoanálise; luta antifascista.

\begin{abstract}
Two years ago, on social media, a paranoid attack on a master's dissertation in education was used to question the rationality of Sciences human productions. From the incomprehension of the Pro Reictory of Research that wanted to understand as a dissertation in the format so dissimilar could be defended. Today, the rationality of all sciences is attacked by a fascist unconscious that installed in the State. Ironically, the authors that attacks the dissertation are now victims of the paranoid installed in the State and identifies as the cause the indoctrination of "social network gurus". In this way, it becomes problematic as a delusion paranoid can potentiate a reactionary unconscious that mainly victimizes that one who produces. Above all, as a denunciation of the reactionary segregative can to shoot potentials revolutionary in scientific research.
\end{abstract}

Keywords: Academic research; schizoanalysis; anti-fascist struggle.

A dissertação Educação Esquizita ${ }^{3}$ desenvolvida no Programa de Pós-graduação em Educação da Faculdade de Educação da UFJF, que usa como armas o referencial teóricometodológico dos trabalhos de Gilles Deleuze e Félix Guattari, mais especificamente, a abordagem metodológica da cartografia e da esquizoanálise, sofre ataques nas redes sociais a partir de maio de 2017. Como efeito, e sob efeito de diversos ataques outros, a instituição, por meio de sua Pró-reitora de Pesquisa, solicita esclarecimento sobre a decisão acerca da aprovação do trabalho naquele dessemelhante formato ao Programa e, por conseguinte, à banca de avaliação, sobretudo, à professora doutora orientadora do trabalho. Isso põe a pensar as políticas de pesquisa e de escrita na academia.

\footnotetext{
${ }^{1}$ Professora Doutora do Programa de Pós-Graduação em Educação - PPGE/UFJF. E-mail: sclareto@ yahoo.com.br.

${ }^{2}$ Doutorando em Educação pelo Programa de Pós-Graduação em Educação - PPGE/UFJF, Bolsista UFJF. E-mail: tarcisiodumont@yahoo.com.br.

${ }^{3}$ MENDES, Tarcísio Moreira. Uma formação esquizita. uma educação bricouleur: processo ético e estético e político e econômico. Dissertação (mestrado acadêmico). Universidade Federal de Juiz de Fora, Faculdade de Educação, Programa de Pós-Graduação em Educação, 2015. Disponível em: https://repositorio.ufjf.br/jspui/handle/ufjf/231. Acesso em: 30 de out. de 2019.
} 
Exercita-se aqui o engendramento do pensar no pensamento acadêmico: um movimento de produção de pensares outros, distintos do pensamento hegemônico da área das Ciências Humanas, mais especificamente, da Educação. A pesquisa cartográfica ou esquizoanalítica praticada na dissertação se coloca como um movimento em relação com o fora: o fora da pesquisa, o fora do já pensado, o ainda não pensado. Um fora que se coloca como resistência aos modos hegemônicos de pesquisar como a pesquisa que busca a solução de problemas e a pesquisa que busca por invariantes, universais. A dissertação Esquizita pensa o funcionamento de um trabalho acadêmico como uma maquinaria que se põe, neste âmbito, a produzir possíveis que aumentem a potência de vida, ou nas palavras do filósofo Spinoza, que promova paixões alegres. A dissertação em questão se põe a pensar uma educação esquizita para os modelos que pretendem impor um único modo semelhante de pesquisa. Propõe-se, também, a uma formação bricoleur: como um artista da bricolagem, o pesquisar se exercita como formação de livre associação. Um corpo nu no território da educação põe a pensar educação junto à arte da performance ${ }^{4}$. Força limites entre a Racionalidade e outras faculdades, apostando num inconsciente maquínico à espreita dos riscos entre movimentos nomádicos e paranoicos. "O uso nomádico e plurívoco das sínteses conjuntivas opõe-se ao uso segregativo e bi-unívoco. $\mathrm{O}$ delírio tem como que dois polos, racista e racial, paranoico-segregativo e esquizo-nomádico. E entre os dois, tantos deslizamentos sutis e incertos, nos quais o próprio inconsciente oscila entre suas cargas reacionárias e suas potencialidades revolucionárias" (DELEUZE; GUATTARI, 2010a, p. 144). Que efeitos são produzidos no encontro entre performance e educação? Paranoico-segregativo ou esquizo-nomádicos?

Assusta-nos e nos causa grande estranheza em relação ao processo midiático das chamadas "redes sociais" de onde parte uma "denúncia" em relação à referida dissertação. Tal denúncia se espalha rapidamente, roubando a atenção das tais redes sociais e, por conseguinte, do território acadêmico. Opiniões são emitidas sem que a dissertação seja sequer lida - uma paranoia midiatizada. "Assim se constitui uma tal trama que tudo o que não passa pela trama não pode, materialmente, ser ouvido. Por exemplo, em um programa sobre as prisões, ficará estabelecido as escolhas jurista-diretor de prisão, juiz-advogado, assistente social-caso interessante, sendo a opinião do prisioneiro médio que povoa as prisões rejeitada fora da trama ou do assunto. É nesse sentido que sempre se 'dá mal' com a televisão, perde-se de antemão. Até mesmo quando se acredita falar por si, fala-se sempre no lugar de um outro qualquer que não poderá falar" (DELEUZE; PARNET, 1998, p. 17). Sites, blogs e páginas em facebook se ocupam com um policiamento ideológico e moral, um tribunal se institui, no qual tudo o que passa fora da trama é rejeitado - bi-unívoco e segregativo. A dissertação trata de política, de uma micropolítica que desdobra macropolítica de pesquisa, que se coloca como uma prática, uma ação política na construção de uma vida e de uma educação que aumentem a potência de agir no mundo, em variação, em que a diferença se coloca na promoção de diferença - aposta em potencialidades revolucionárias.

O site que divulgou indiscriminadamente os ataques à dissertação diz que se dispõe a fazer Ciência com racionalidade. Entretanto, não se ocupou em checar qualquer informação ou ouvir o que os autores do trabalho teriam a dizer. O mínimo de ética de quem se dispõe a fazer jornalismo ou produzir pensamento dito crítico: ouvir contraditórios, ser plurívoco. Hoje, com a explosão daquilo que já naquela época se mostrava, o fascismo ocupando redes sociais e meios de notícias e jornalismo, os que atacaram a dissertação nas redes sociais com seu relativismo nada científico, agora se veem vítimas do fascismo que alimentaram dentro das universidades

\footnotetext{
${ }^{4}$ Vídeo "Performance de uma qualificação de Mestrado em Educação", fragmento do exame de qualificação de mestrado apresentado em 26 de março de 2014, ao Programa de Pós-Graduação em Educação da UFJF. Disponível em: https://www.youtube.com/watch?v=k3zOtrWo8R4. Acesso em: 24 de out. de 2019.
} 
e fora delas. Hoje, denunciam as atrocidades dos blogueiros reacionários do YouTube ${ }^{5}$, os mesmo que usaram os textos do site Racionalista para dizer que o autor faria doutrinação política partidária em sala de aula ${ }^{6}$. Loucura, não!? Agora, se põem como vítimas de "pesquisadores" que acreditam que a Terra é plana, que descendemos de Adão e Eva e que o aquecimento Global é uma estratégia globalista da esquerda culturalista para dominar o mundo. Veem-se vítimas do relativismo acadêmico que diziam combater ${ }^{7}$, mas que, com suas práticas, ajudaram a endossar. Isto porque ao negarem o mínimo de racionalidade científica para atacar, inclusive, aquilo que diziam não ser científico, abriram uma empreitada que, neste momento, é difícil de ser enfrentada - um tipo de "psicose reacional", "Parece-nos que, nos casos apresentados aqui, o acontecimento desencadeante é primeiramente a atmosfera sangrenta, impiedosa, a generalização de práticas desumanas, a impressão tenaz que as pessoas têm de assistir a um verdadeiro apocalipse" (FANON, 2005, p. 290). O quadro descrito por Fanon como causa das doenças psíquicas de seus pacientes, vítimas do quadro de guerra na época da libertação da Argélia, serve-nos para compreender o campo de conflito que se intensificou na sociedade brasileira, óbvio, como desdobra de uma conjuntura mundial, após o golpe 2016. Termos como "desgraça", "desprestígio", "doutrinação", "perigo" usados pelos autores dos textos "críticos", assim como os ataques pessoais e perseguição nas redes sociais com muitas palavras de baixo calão e de violência explícita como estrupo e tortura, dão o tom do estado de guerra instituído em nossa sociedade acadêmica.

Este artigo não vai se ater aos ataques medíocres à honra das pesquisadoras envolvidas na elaboração da dissertação de mestrado; nem mesmo na perseguição que se seguiu por distintas redes sociais, sempre contendo muita violência e discurso de ódio. Apesar de que esses são pontos importantes para se compreender a dinâmica e os mecanismos de funcionamento das chamadas redes sociais: tudo vira barril de pólvora e a destruição de tudo que cerca, um "indesejado", é o desejo maior, prática constante, caminho trilhado - inconsciente paranoico como efeito da psicose reacional instalada. Na diferença disso, tratará do teor, nada científico, do ataque e de seus contra-efeitos àqueles que o produziram.

O primeiro aspecto em destaque é a própria dinâmica de validação da produção acadêmica: a análise e avaliação pelos pares. Por se referirem a uma produção de uma comunidade acadêmica, a avaliação das teses e dissertações sempre são feitas por doutores da área, que têm condição científica e titulação acadêmica para analisar o recorte escolhido, as fontes pesquisadas, a metodologia usada e, certamente, a inovação que tal pesquisa traria para área. $\mathrm{O}$ autor do primeiro ataque paranoico delirante reconhece tal competência, porém, não lança mão deste modo de proceder. Não consulta a comunidade acadêmica, nem mesmo especialistas da área. Ao que parece, o autor do texto delira que ele mesmo teria condições, sozinho - com seus gostos e preferências, ideologias e moralidades, bi-unívoco e segregativo de fazer tal ataque à dissertação, assim como à academia, ao campo das Ciências Humanas e seus modos de proceder, sugerindo, inclusive, que a banca fosse destituída. Loucura, não!?

$\mathrm{O}$ ataque usou a dissertação para justificar o desprestígio acadêmico a que as Ciências Humanas são, historicamente, acusadas em comparação às Ciências ditas Exatas ou Naturais. Aqui, problematizaremos as análises e os usos de apenas algumas partes de toda a dissertação,

\footnotetext{
5 Não são os professores que estão doutrinando os alunos. São os gurus de redes sociais. Disponível em: https://universoracionalista.org/nao-sao-os-professores-que-estao-doutrinando-jovens-sao-os-gurus-de-redessociais/. Acessado em 03 de mai. de 2020.

6 CONSTANTINO, Rodrigo. A desgraça de nossa educação e o "vale tudo" na área de humanas. https://www.gazetadopovo.com.br/rodrigo-constantino/artigos/desgraca-de-nossa-educacao-o-vale-tudo-na-areade-humanas/. Acessado em 03 de mai. 2020.

${ }^{7} \mathrm{O}$ presente de grego de bolsonaro às Universidades. Disponível em https://universoracionalista.org/o-presentede-grego-de-bolsonaro-as-universidades/. Acessado em 03 de mai. 2020.
} 
foram elas: o Resumo, que traz um recorte do texto "Água Viva" de Clarice Lispector; o ABSTRACT que exigia que a leitora ou leitor aprendesse a ler Português e escrito em Língua Inglesa; e um vídeo com um trecho de uma ação de arte da performance. Chamamos atenção ainda para o local no qual foi hospedado o ataque ou a crítica "científica", um sítio particular na internet. Segundo o autor do ataque, era absurdo que um pesquisador, financiado pela Capes, produzisse um trabalho de dissertação com estes aspectos - Resumo, Abstract e Arte da Performance nu - e que isso contribuía para o desprestígio das Ciências Humanas na Academia. Inclusive, um outro blogueiro reacionário, apoiador deste governo inimigo das Universidades Públicas, relacionou, a partir do primeiro texto publicado, a pesquisa de mestrado a professores que fariam doutrinação "petista" e "psolista" (sic) nas universidades. Hoje, o site da razão científica tenta denunciar os ataques do atual governo federal, que chama professores de doutrinadores, contra-argumentando que os verdadeiros doutrinadores não são os professores, mas os "gurus de redes sociais" (sic). Quer dizer: um site de uma rede social, que atacou uma pesquisa acadêmica de um professor universitário, dizendo para outro perfil de rede social que ataca professores universitários, que o problema não são os professores universitários que pesquisam, mas os gurus das redes sociais. Ironia, não!?

Talvez se, como em toda revista qualificada de divulgação científica, o site, que se considera defensor da "boa Ciência", contasse com um grupo mínimo de editores ou de pareceristas qualificados, erros básicos, como falta de revisão bibliográfica e clareza nos métodos de análise nos seus textos divulgados, não fossem cometidos. Aqui a semelhança entre o modus operandi dos gurus terra-planistas das redes sociais e dos gurus das redes sociais racionalistas é grande, pois em ambos faltam um corpo qualificado formado por pares da área. Aspecto importante, já que o autor do ataque, inclusive, cita o conhecido caso de Alan Sokal. Em 1996, Sokal teve um artigo que misturava pós-modernidade (vá saber que é isso) e gravidade quântica aceito num famoso periódico de estudos culturais, para provar a falta de rigor científico da área. $\mathrm{O}$ autor do ataque à dissertação expressa sua suspeita, dizendo que tinha a esperança que a dissertação teria também tal metodologia e objetivo. Nem tanto...

A dissertação dessemelhante longe de desejar ser uma mentira para impor uma verdade universal é antes uma verdade para denunciar a ilusão da verdade universal. Ou antes, aponta que o desejo de rigor científico revolucionário consciente nem sempre é garantia de similitude com o rigor inconsciente reacionário. Neste sentido, talvez se o autor do ataque tivesse mais afinidade com área de produção da dissertação, apostasse mais no inconsciente nomádico que num inconsciente bi-unívoco, envenenado por jargões pós-modernos e não cometesse um dos erros mais graves e fundamentais de uma pesquisa científica: errar o nome do autor da pesquisa criticada e confundir as etapas da pesquisa, defesa de mestrado com exame de qualificação.

O trabalho dessemelhante ocupa a Academia para produzir outras academias, exercitando-se em outras leituras e escritas. Desse modo, convoca um/a leitor/a por vir, um/a leitor/a que falta, que maquine sua criação, que esteja disposto/a a produzir corpo outro junto à experienciação da leitura. Poderíamos sustentar que a dissertação sabia que causaria discussão. O que não seria verdade, dada a escuta ao alerta que Deleuze e Guattari, em seu brilhante “O que é a Filosofia?” (2010b), já fizera: "Que alguém tenha tal opinião, e pense antes isto que aquilo, o que isso pode importar para a filosofia, na medida em que os problemas em jogo não são enunciados? E quando são enunciados, não se trata mais de discutir, mas de criar indiscutíveis conceitos para o problema que nós nos atribuímos. A comunicação vem sempre cedo demais ou tarde demais, e a conversação está sempre em excesso, com relação a criar. Fazemos, às vezes, da filosofia a ideia de uma perpétua discussão como 'racionalidade comunicativa' ou como 'conversação democrática universal'. [...] Mas aqueles que criticam sem criar, aqueles que se contentam em defender o que se esvaneceu sem saber darlhe forças para retornar à vida, eles são a chaga da filosofia. São animados pelo ressentimento, todos 
esses discutidores, esses comunicadores. Eles não falam senão deles mesmos, confrontando generalidades vazias. A filosofia tem horror a discussões. Ela tem mais que fazer. O debate lhe é insuportável, não porque ela é segura demais de si mesma: ao contrário, são suas incertezas que a arrastam para outras vias mais solitárias" (DELEUZE; GUATTARI, 2010b, p. 37-38). A filosofia tem horror às discussões! A dissertação está mais ocupada em investir nas incertezas que impor novas certezas. A dissertação se ocupa em fazer ciência ou pensar outros modos de fazer ciência, sem pretender criar um Método Universal, uma Ciência Racionalista, um único modo de pensar ou a certeza de que nada mais vale. "Não somos científicos. Fazemos outra coisa. Que fazemos então?" questiona um dos platôs da dissertação. Embora tenhamos ciência de que sua produção não é direcionada especificamente a um grupo de intelectuais ou de pessoas, mas a quem se interessar. É isso. A dessemelhança aqui não é afronta de um delírio adoecido, paranoico-segregativo que pensa ter criado um novo parâmetro para determinar quem é ou não cientista, que é ou não Ciência, desejo autoritário, fascista. Pelo contrário, a dessemelhança produzida pela dissertação pretende sim potencializar modos outros de vida, esquizo-nomádico, denunciar modos adoecidos e limitantes de pesquisa, potencializar devires revolucionários na pesquisa acadêmica, sem relativismos academicistas mascarados de cientificidade.

Assim, o argumento de que a pesquisa foi financiada com dinheiro público e por isso daria a qualquer contribuinte o direito de questioná-la é verdade. Tão verdade como questionar o sistema educacional privado financiado por dinheiro público por meio de renúncias fiscais e que não tem permitido que futuros cientistas saiam minimamente formados e aptos a questionamentos éticos e científicos. Uma leitura breve e atenta do texto "Aparelho de Captura" de Deleuze e Guattari, no livro Mil Platôs, vol. 5 (2012), ajuda a perceber que nada produzido por nossa sociedade atual é possível sem a atuação do Estado, nem mesmo o dito sem rosto Mercado, que necessita de um Estado Mínimo para os donos do dinheiro, para que o Mercado funcione. Desse modo, dizer que apenas pesquisas produzidas com financiamento direto de agências de fomento seriam passíveis de crítica é falso. Aqui falamos de formação de cientistas e produção de conhecimento, é isto que dissertação problematiza, e isso é interesse Público, não Privado. Ou, do contrário, estaríamos abrindo precedente para que resultados de pesquisas financiadas por agências privadas não fossem questionadas. Aqui um alerta e que tem a ver com o ataque que as Universidades Públicas têm sofrido: é preciso prudência para que não nos tornemos vítima do desejo de destruição de nós mesmos. Pois sim, a dissertação tem um desejo de destruir, mas não destruir tudo e a qualquer custo. Deseja destruir certezas e, sobretudo, destruir formas que impedem outras vidas de serem possíveis. Uma coisa que a Ciência nos ajuda a pensar e que parecia ser a primeira ocupação do ataque à dissertação, é em um rigor com aquilo que produzimos. Dito de outra maneira, a produção tem que estar à altura de sua própria produção, não cabendo um relativismo tacanho, falseado num academicismo raso, apoiado em likes do facebook, seja de um grupo de reacionários racionalistas ou reacionários terra-planistas. Se hoje os racionalistas denunciam os ataques às Ciências produzidos por gurus das redes sociais, é necessário também que, racionalmente, compreendam que algumas de suas ações, no passado, alimentaram esta consciência segregativa, reacionária, fascista que neste momento corta verbas de financiamento público para as Ciências Humanas, convoca manifestações por atos institucionais de censura, destituição do Congresso e fechamento do STF. Neste sentido, é bom lembrar a grande diferença que Deleuze e Guattari produzem para designar um Estado fascista dos outros - o desejo de abolição total. Um movimento fascista, seja ele mais racionalista ou irracional, quando se vê impedido de desejar e vendo que não tem saída, deseja que todos os desejos morram também.

O embate na Academia tem sido sempre entre uma Ciência Maior - aparelho paranoicosegregativo, consCiência - e uma ciência menor - esquizo-nomádica, inconsciente - que sempre funciona uma em relação a outra, em coexistência, em deslizamento entre um polo e 
outro. Uma pesquisa dessemelhante produz um texto que maquina modos outros de viver e fazer educação e pesquisar em educação junto à arte, combatendo os desejos reacionários, conjurando a formação de aparelhos de Estado, apostando na plurivocidade para continuar a disparar potencialidades revolucionárias na pesquisa acadêmica. No entanto, como vimos em maio de 2017 e como temos acompanhado ao longo desses últimos anos, a conjuração da formação de aparelho de Estado, a movimentação de uma máquina de guerra, quando tem a guerra como fim, devem perversa e reacionária destruindo tudo, sem capacidade de criar uma nova terra. O desafio é então ter como horizonte os perigos da captura do aparelho de Estado instituição do único Método a ser seguido - conjurando sua formação e, ao mesmo tempo, apostando na variação contínua da máquina de guerra, que não pode ter a guerra como fim, para que não devenha enlouquecida, fascista. Parafraseando Michel Foucault no prefácio escrito à edição francesa de "O anti-Édipo", a dessemelhança aqui é uma introdução à vida não fascista na Academia que deseja libertar toda ação política da forma paranoica e totalizante, apostando no desejo como proliferação fugindo à hierarquização piramidal e à segmentação, ao Negativo como Falta, Erro e Falso; apostemos na alegria dos encontros que multiplicam as vidas possíveis; e, por fim, "não caia de amores pelo Poder".

\section{Referências}

DELEUZE, Gilles; GUATTARI, Félix. O anti-Édipo: capitalismo e esquizofrenia 1. Trad. Luiz B. L. Orlandi. São Paulo: Editora 34, 2010a.

DELEUZE, Gilles; GUATTARI, Félix. O que é a filosofia? Trad. Bento Prado Jr. e Alberto Alonso Muñoz. São Paulo: Editora 34, 2010b.

DELEUZE, Gilles; GUATTARI, Félix. 7.000 a. C. - aparelho de captura. In.: DELEUZE, G; GUATTARI, Félix. Mil platôs: capitalismo e esquizofrenia 2, vol. 5. Trad. Peter Pál Pelbart e Janice Caiafa. São Paulo: Editora 34, 2012. p. 119-190.

DELEUZE, Gilles; PARNET, Claire. Uma conversa, o que é, para que serve? In: DELEUZE, Gi. Diálogos. Trad. Eloisa Araújo Ribeiro, São Paulo: Escuta, 1998. p. 02-29.

FANON, Frantz. Os condenados da terra. Trad. Enilce Albergaria Rocha, Lucy Magalhães. Juiz de Fora: Editora UFJF, 2005.

MENDES, Tarcísio Moreira. Uma formação esquizita. uma educação bricouleur: processo ético e estético e político e econômico. Dissertação (Mestrado Acadêmico). Universidade Federal de Juiz de Fora, Faculdade de Educação, Programa de Pós-Graduação em Educação, 2015. Disponível em: https://repositorio.ufjf.br/jspui/handle/ufjf/231. Acesso em: 30 de out. de 2019. 